Please do not remove this page

RMIT

UNIVERSITY

\title{
F-shaped shorted patch antenna with dual-frequency characteristics
}

Lal, Jayshri; Kan, Hing; Rowe, Wayne; Chung, Alan

https://researchrepository.rmit.edu.au/esploro/outputs/9921862450501341/filesAndLinks?institution=61RMIT_INST\&index=null

Lal, J., Kan, H., Rowe, W., \& Chung, A. (2006). F-shaped shorted patch antenna with dual-frequency characteristics. IEEE TENCON 2006, 1-3. https://doi.org/10.1109/TENCON.2006.344034

Published Version: https://doi.org/10.1109/TENCON.2006.344034

Repository homepage: https://researchrepository.rmit.edu.au

(c) 2006 IEEE. Personal use of this material is permitted. However, permission to reprint/republish this material for advertising or promotional purposes or for creating new collective works for resale or redistribution to servers or lists, or to reuse any copyrighted component of this work in other works must be obtained from the IEEE.

Downloaded On 2023/04/26 23:14:19 +1000 


\title{
F-shaped Shorted Patch Antenna with Dual-frequency Characteristics
}

\author{
J. Lal ${ }^{1}$, H. K. Kan ${ }^{1}$, W. S. T. Rowe ${ }^{2}$ and K. L. Chung ${ }^{3}$ \\ ${ }^{1}$ School of Engineering \& Physics, University of the South Pacific, Suva, FIJI \\ ${ }^{2}$ School of Electrical \& Computer Engineering, RMIT University, Melbourne, AUSTRALIA \\ ${ }^{3}$ Dept. of EIE, Hong Kong Polytechnic University, HONG KONG \\ E-mail: hingkan@ieee.org
}

\begin{abstract}
This paper presents a compact shorted patch antenna. The antenna is based on an F-shaped printed conductor coaxially fed with an electromagnetically coupled shorted inverted F-shaped antenna interleaved with each other. The overall antenna is then coupled with a rectangular ring. The antenna has dual characteristic features and its resonance frequency is at $1.85 \mathrm{GHz}$ and $2.42 \mathrm{GHz}$. The measured return loss bandwidth and its far field radiation patterns are presented. The gain of the antenna is $1.6 \mathrm{dBi}$.
\end{abstract}

\section{INTRODUCTION}

With the recent proliferation of wireless communicating enabling portable devices, it is essential that the device looks aesthetically pleasing and be able to operate at multiple applications (for example, mobile communication and Bluetooth). Antenna designers are faced with the task of designing small antenna and that can operate in at least two frequencies. There are many circumstances and advantages in utilizing shapes that are neither circular nor rectangular for radiating patches in microstrip antennas design [1] due to the space constraints of the portable device. Some of these shapes include the ' $H$ ' shaped patch and the ' $E$ ' shaped patch. A meandered F-shaped patch as well as miniaturized printed circuit board wire antenna was investigated for WLAN and bluetooth applications [2]. It was shown that a $57 \%$ reduction in the total area was achieved when compared to that of an inverted $F$ antenna [2]. However, the resulting solution yielded a single operating frequency. Recently, a dual-frequency shorted patch antenna was presented [3]. The antenna utilized slot to generate the second resonance on the antenna.

In this paper, an F-shaped printed antenna is proposed. The antenna consists of an interleaved straight F-shaped printed conductor and an inverted shorted F-shaped antenna. The present configuration reduces the overall surface area occupied by the microstrip patch antenna instead of a wire antenna. The introduction of radiating slots in the F-shape conductor contributes to the reduction in the antenna size. A further reduction is achieved in the interleaved F-shaped antenna by utilizing shorting pins in close proximity to the coaxially fed antenna. The overall size of the antenna is $0.173 \lambda_{0} \times 0.185 \lambda_{0} \times 0.045 \lambda_{0}$ (where $\lambda_{0}$ is the free space wavelength of the antenna).

\section{CONFIGURATION AND DESIGN STRATEGY}

Figure 1 shows the schematic diagram of the proposed interleaved F-shaped shorted patch antenna. As can be seen from Figure 1a, the antenna has an overall length, $\mathrm{L}=28$ $\mathrm{mm}$ and width, $\mathrm{W}=30 \mathrm{~mm}$. The concept of this antenna is based upon the principal of any dual resonance antenna, namely, that if a mutual resonance can be formed; the overall impedance variation of the antennas will be minimized enhancing the impedance bandwidth of the shorted patches [4]. The antenna here consists of two patches, namely, an F-shaped probe fed patch and an electromagnetically coupled inverted F-shaped patch. In a typical F-shaped printed antenna, there are two regions where radiation takes place. This is the horizontal arm and the vertical arm of the F-shape. To further enhance its bandwidth, an inverted F-shaped patch is coupled to the main radiating patch. This acts as the parasitic patch and radiates mainly due to the horizontal arm. Due to the mutual coupling between the radiators, the impedance bandwidth is enhanced. The parasitic ring around the main patch also contributes to the total radiation of the antenna. By incorporating several radiating slots, the bandwidth of the antenna is enhanced. The traditional method of embedding shorting pins in close proximity to the radiating edges of the F-shaped antenna is employed here. It is interesting to note that when the shorting pin is removed from the inverted patch, the resonant frequency is increases by $0.85 \lambda_{f r}$. Large conductor size reduction is achieved in this proposed configuration by maximizing the current path on each printed conductor. To couple power into the antenna, the straight F-shaped patch was connected by a probe feed. This is done here by connecting conducting pins through the dielectric material from the ground plane onto the antenna port positioned at (xp, yp). The interleaved F-shaped antenna was designed for an input impedance of $50 \Omega$. As can be seen from the side view of the antenna schematic, a thin layer of Rogers TMM $4\left(\varepsilon_{r}=4.5, d=1.27 \mathrm{~mm}\right)$ was used to etch the patches. A Rohacell foam layer $\left(\varepsilon_{r}=1.07, d=6 \mathrm{~mm}\right)$ is sandwiched between the two dielectric layers. The antenna is manufactured and tested.

\section{RESULTS \& DISCUSSIONS}

Figure 2 shows the simulated and measured return loss of the proposed antenna. The simulated results were obtained using the Zeland IE3D Commercial Software Package. As can be seen from the plot, the $-6 \mathrm{~dB}$ (3:1 VSWR) return loss bandwidth of the simulated and measured results are in good agreement with each other in the L band of the frequency spectrum. However, the measured result degrades below 5 $\mathrm{dB}$. This degradation could be due to the small fabrication 


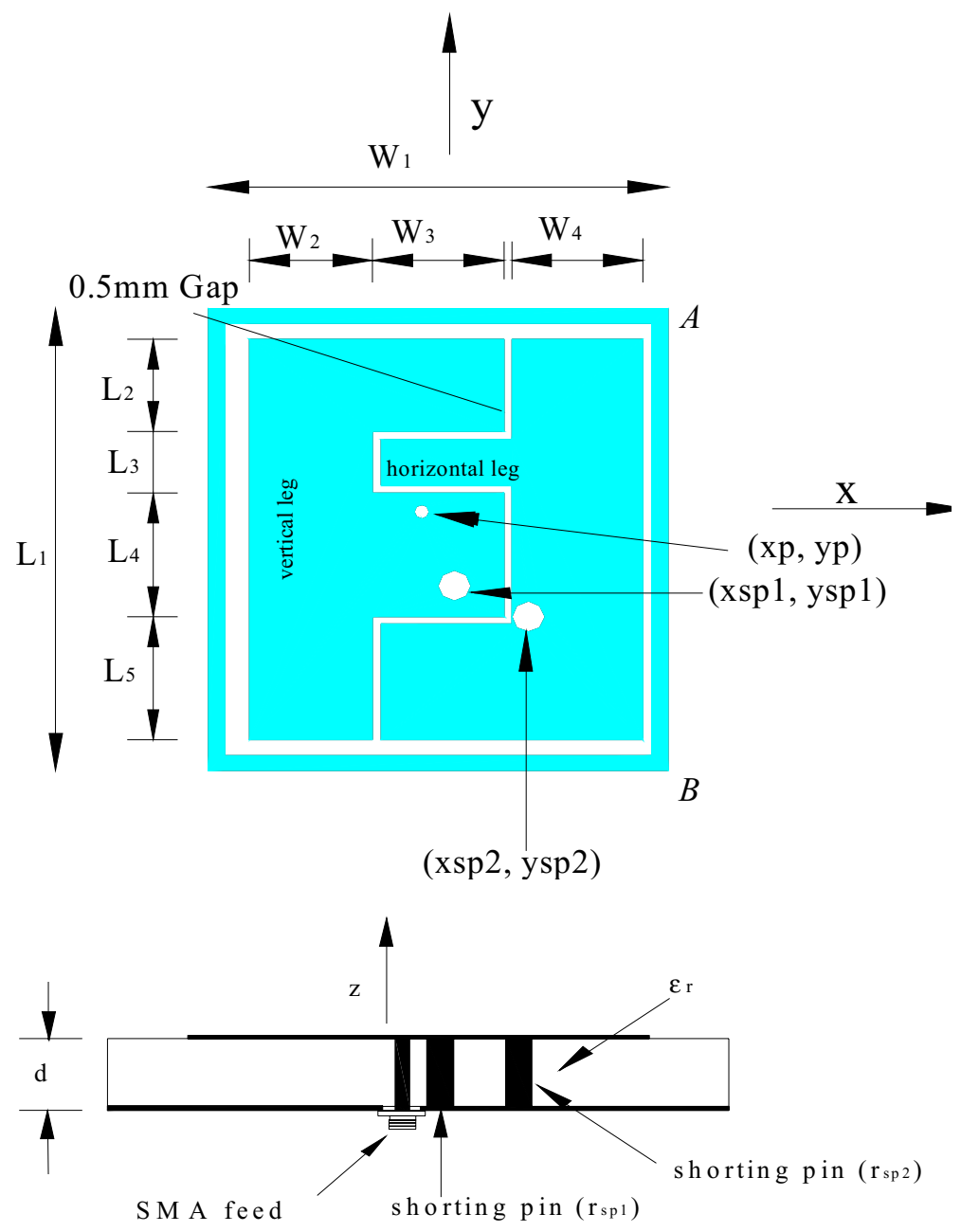

Figure 1: Schematic of proposed F-shaped shorted patch antenna: (a) Top view (b) side view

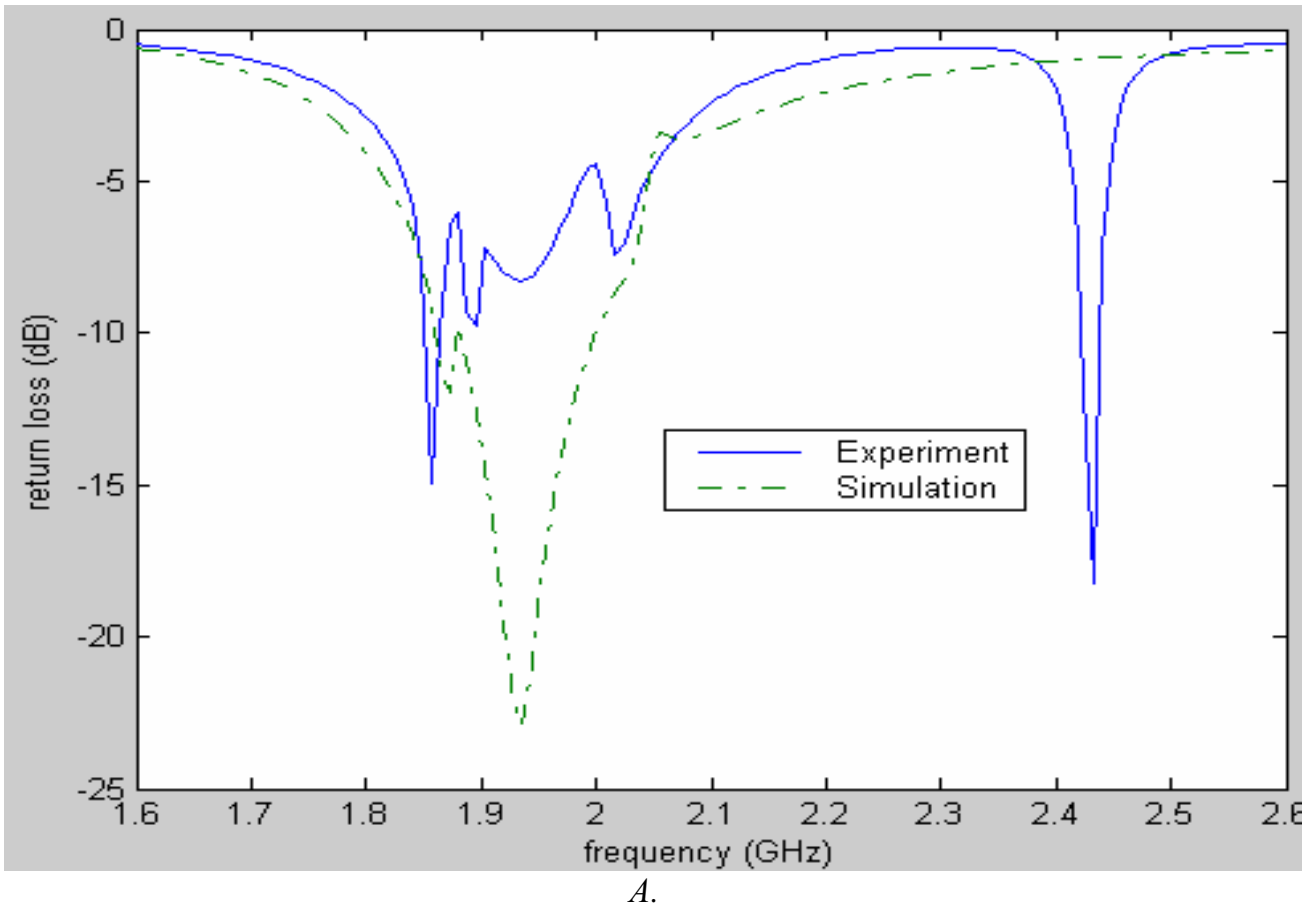

Figure 2 Return loss performance of patch antenna

(Parameters: $x p=14 \mathrm{~mm}, y p=16.8 \mathrm{~mm}, \mathrm{xsp} 1=15 \mathrm{~mm}, \mathrm{ysp} 1=12 \mathrm{~mm}, \mathrm{xsp} 2=19.5 \mathrm{~mm}, \mathrm{ysp} 2=10 \mathrm{~mm}, \mathrm{~L}_{2}=6 \mathrm{~mm}, \mathrm{~L}_{3}=4 \mathrm{~mm}, \mathrm{~L}_{4}=8 \mathrm{~mm}, \mathrm{~L}_{5}=8 \mathrm{~mm}, \mathrm{~W}_{2}=$ $7.5 \mathrm{~mm}, \mathrm{~W}_{3}=8 \mathrm{~mm}, \mathrm{~W}_{4}=8 \mathrm{~mm}, \mathrm{r}_{\mathrm{p}}=0.5 \mathrm{~mm}, \mathrm{r}_{\mathrm{sp}}=1 \mathrm{~mm}$ ) 

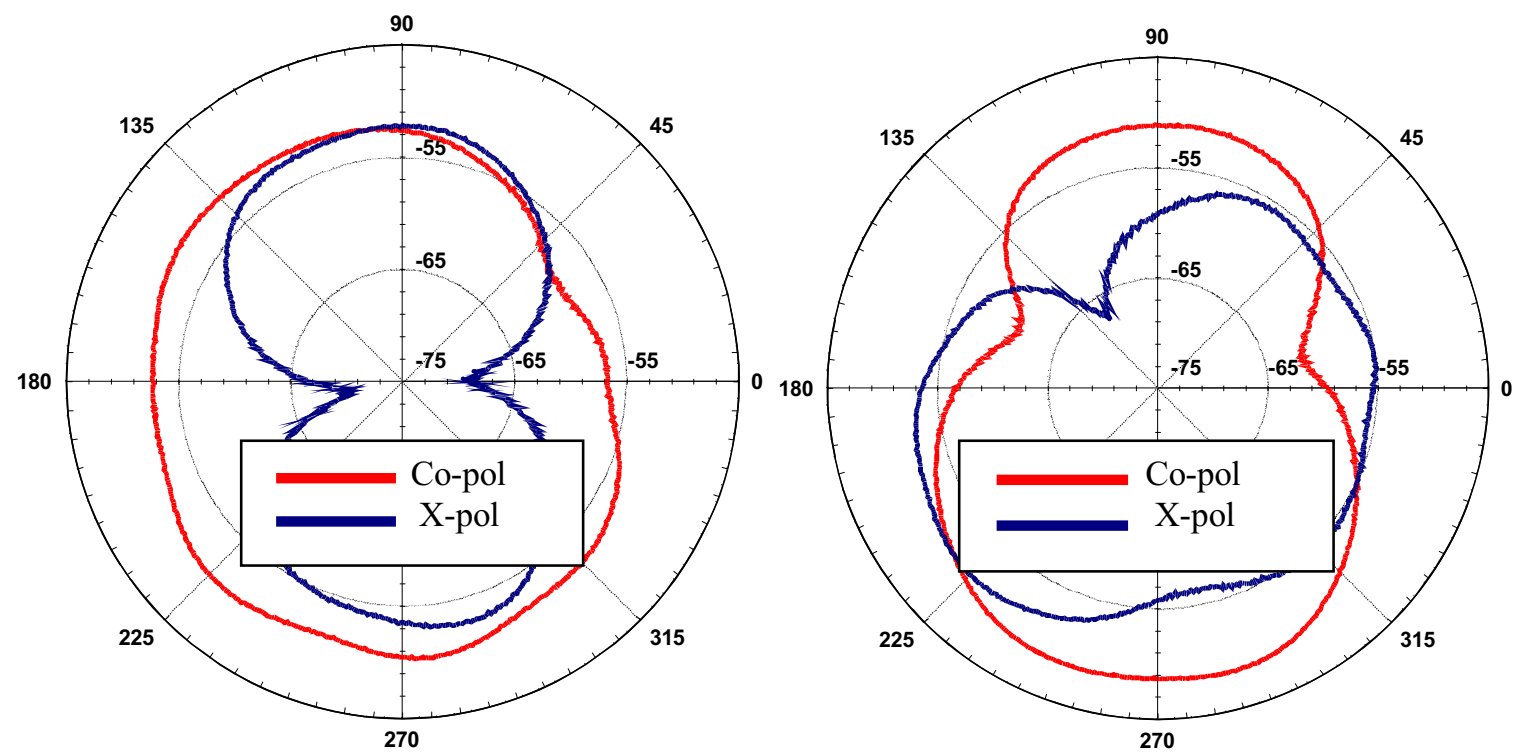

Figure 3 Radiation patterns of the proposed patch antenna: Left: H-plane and Right: E-plane

tolerance associated with this antenna design. As can be seen from Fig. 1, only a $0.5 \mathrm{~mm}$ gap separates the two Fshaped. conductors. Moreover, if the etching is not perfect, degradation in the return loss characteristic is expected. Another tolerance limit is the location of the second shorting pin, i.e. (xsp2, ysp2). If the shorting pin is located even slightly over the edge, the return loss characteristic will degrade. As can be seen from the experimental results, there are two resonant frequencies, namely, at $1.85 \mathrm{GHz}$ and 2.42 GHz. The bandwidth of the antenna is $7.1 \%$ and $1 \%$ for the lower and higher resonance respectively. The two resonant frequencies are due to the two shorting pins used in the antenna configuration.

The far field radiation patterns of the interleaved F-shaped printed antenna were measured at $1.85 \mathrm{GHz}$ at the Royal Melbourne Institute of Technology anechoic chamber and are shown in Fig. 3. The H-plane and E-plane radiation patterns are shown in Fig. 3a and $3 \mathrm{~b}$ respectively. In Fig. 3a, the patterns show that the cross polarization level in the $\mathrm{H}$ plane is relatively high compared to the cross-polarization level in the E-plane in Fig. 3b (note that the broadside is 90 degrees on the plots). The co-polarization levels for both planes are literally omni-directional, however, there are slight dips on the E-plane and can be seen at 10 degrees and 160 degrees on the plots in Fig. 3b. The ground plane of the antenna extends $1 \mathrm{~cm}$ on each side of the printed conductor.
The gain of the antenna at the broadside is $1.6 \mathrm{dBi}$. The patterns also show that the antenna radiates well at the back as well. The gain at the back of the antenna is $2.6 \mathrm{dBi}$.

\section{CONCLUSION}

An interleaved $\mathrm{F}$-shaped printed antenna with dual resonance characteristic has been presented. The interleaved patches are enclosed with a rectangular parasitic ring to further improve the bandwidth performance. The antenna resonance is at $1.85 \mathrm{GHz}$ and $2.42 \mathrm{GHz}$ with its impedance bandwidth of $7.1 \%$ and $1 \%$ (3:1 VSWR) for the lower and higher frequency respectively. The measured gain of the antenna is $1.6 \mathrm{dBi}$ at $1.85 \mathrm{GHz}$.

\section{REFERENCES}

[1] S. A. Long, J. Ou and W. F. Richards, "A theoretical and experimental investigation of annular, annular sector, and circular sector microstrip antennas", IEEE transactions on Antennas \& Propagation, vol. 32, pp. 864-867, 1984

[2] H. Y, Yang, "Miniaturized printed wire antenna for wireless communications", Department of Electrical and computer Engineering, University of Illinois, Chicago.

[3] H. K. Kan, D. Pavlickovski, R. B. Waterhouse and W. S. T. Rowe, "small dual-frequency shorted patch antenna", Micro. Opt. Tech. Letts, vol. 48 (6), pp. 1225-1227, June 2006

[4] H. K. Kan, "Small printed antennas for wireless communication handset terminals", PhD Dissertation, School of Electrical and Computer Engineering, RMIT University, 2001, Australia. 